\title{
Pathways to Employment and Quality of Life for Apprenticeship and Traineeship Graduates with Disabilities
}

\author{
Errol Cocks* , Stian H. Thoresen, and Elinda Ai Lim Lee \\ Centre for Research into Disability and Society, School of Occupational \\ Therapy and Social Work, Curtin University, Western Australia, Australia
}

People with disabilities have low participation rates in employment and vocational education and training. Thirty adults with disabilities were sampled from an Australian longitudinal study of economic and social outcomes achieved by graduate apprentices and trainees. Participants were surveyed and interviewed to identify pathways from high school to 12-months post-graduation, and completed the Quality of Life Questionnaire (QOL.Q). Career pathways incorporated experiences facilitating career development including continuous engagement in vocational activities, and support from school personnel and external disability agencies. A year following graduation, $87 \%$ were in paid work, 53\% remained with the training employer, and $40 \%$ continued with vocational education. Positive quality of life (QoL) outcomes were associated with employment, employee benefits, and satisfaction with work and social connections. Our research demonstrated that apprenticeships and traineeships led to positive graduate employment outcomes and career pathways for adults with disabilities. Positive employment outcomes were associated with enhanced QoL for participants.

Keywords: Apprentices and trainees; Australia; case studies; facilitating career development; employment benefits; pathways from school to work; people with disabilities; quality of life;

\section{Introduction}

Employment is an important pathway to social inclusion, and is strongly associated with positive mental health, improved self-esteem, and quality of life (QoL) (Evans \& Repper, 2000; Falba, Sindelar, \& Gallo, 2009; Merton \& Bateman, 2007; Virtanen et al., 2008; Zabkiewicz, 2010). It provides financial benefits, a sense of purpose and belonging, an important social context, and status and recognition, all of which have a positive impact on

\footnotetext{
*Corresponding Author. Email: e.cocks@curtin.edu.au
} 
QoL (Evans \& Repper). On the other hand, unemployment has been associated with poverty, distress, anxiety, and somatization (ACOSS, 2013). Persons who have experienced long term unemployment believe that they are seen as less valuable by society and feel socially excluded (Barišin, Benjak, \& Vuletić, 2011). People with disabilities are even more disadvantaged.

People with disabilities occupy disadvantaged positions in the labour market (Campolieti, 2002; Jones, Latreille, \& Sloane, 2006; Kidd, Sloane, \& Ferko, 2000; Wilkins, 2004). They face multiple challenges and obstacles when seeking employment, including discrimination, misconceptions regarding their work capacities, negative employer attitudes, and lack of disability friendly workplaces (Deloitte Access Economics, 2011; Gold, Shaw, \& Wolffe, 2005; Lewis, Thoresen, \& Cocks, 2011b; Moore, Konrad, Yang, Ng, \& Doherty, 2011). Economic and labour market changes have made it more difficult to retain employment and become re-employed (OECD, 2010; Sciulli, Gomes de Menezes, \& Vieira, 2012). People with physical disabilities who were involuntarily unemployed have been found to experience double jeopardy for depression compared to non-disabled individuals (Turner \& Turner, 2004).

Australia compares unfavourably with other OECD countries in labour market participation by people with disabilities, particularly those receiving disability benefits (OECD, 2010). In 2012, 53\% of people with disabilities were in the labour force (employed or looking for work) compared to $83 \%$ of the non-disabled population and the unemployment rate was $9.4 \%$ compared to $4.9 \%$ (ABS, 2013). Apart from health or disability issues, the lack of necessary skills or education have been identified as the main barriers to participation in work (ABS, 2012). Australian research has indicated that employers who were positively inclined to hire people with disabilities were uncertain that the workplace could adequately support an employee with disabilities and were unaware of available government supports 
(Waterhouse, Kimberly, Jonas, \& Glover, 2010). Relatedly, the participation rate of people with a disability in apprenticeships and traineeships remains low, representing between $1.2 \%$ and 2.3\% of commencements between 1998 and 2010 (NCVER, 2011b). Just over 14\% of working-age Australians (15-64 years) have a disability (ABS, 2013), but only $1.4 \%$ of apprentices and trainees self- identified as having a disability in 2010 (NCVER).

Work-based training such as apprenticeships and traineeships is an effective pathway to employment for people with disabilities and has been linked to positive outcomes (Cocks \& Thoresen, 2013a, 2013b; Cocks, Thoresen, \& Lee, 2013; Lewis, Thoresen, \& Cocks, 2011a). When people with disabilities receive training and become employed, their financial position and access to financial services are improved, they have enhanced purchasing power and capacity to contribute to society, may enjoy a better QoL, and welfare costs are reduced. This article reports on pathways followed by people with disabilities from school to work via completion of apprenticeships or traineeships, and outcomes associated with QoL. The study drew a small sample of participants from a national Australian longitudinal study which examined social and economic outcomes for apprentices and trainees with disabilities.

\section{Background}

\section{Employment and Quality of Life}

QoL is a relative term that conveys different meanings to different people. There is no consensus as to meaning (AIHW, 2012) although there is general agreement of the multidimensional nature of QoL (Chow, Lo, \& Cummins, 2005). The complexity of the term is conveyed by Barišin et al. (2011), that “quality of life implies satisfying one’s needs and interests, choice of values, and aspirations in different areas and in different stages of life” (p. 551). Factors that can influence a person's perception of their own QoL include physical health, psychological wellbeing, levels of independence and functioning, social support network, material resources, and personal beliefs (AIHW). Personal values, life conditions, 
and life satisfaction interact to determine QoL (Felce \& Perry, 1995). Based on three aspects of life experiences that influence a person's perceived QoL, personal characteristics, objective life conditions, and the perceptions of significant others, Schalock and Keith (1993 and 2004) developed the Quality of Life Questionnaire (QOL.Q). The QOL.Q is an instrument to measure the QoL experienced by persons with intellectual and developmental disabilities in four major dimensions: (1) satisfaction; (2) competence/productivity; (3) empowerment/independence; and (4) social belonging/community integration. The QOL.Q was used as a measure in this study because it contains norm scores for people with developmental and intellectual disabilities and validation for people with disabilities in Australia, the United States and other countries. In addition, as the competence/productivity dimension of the QOL.Q has a strong vocational focus, this instrument served the purpose of this research looking at the relationship between employment and QoL. In addition, there is a strong research evidence base for the QOL.Q providing reliable and validated studies of QoL for people with developmental disabilities internationally (e.g., Campo, Sharpton, Thompson, \& Sexton, 1996, 1997; Eggleton, Robertson, Ryan, \& Kober, 1999; Kober \& Eggleton, 2005; Rapley \& Lobley, 1995; Verdugo, Prieto, Cabello, \& Pelaez, 2004).

Research has confirmed the relationship between QoL and employment for people with disabilities. Barišin et al. (2011) found that there was a significantly lower self-assessed health-related and overall QoL for unemployed women with disabilities. Work status influenced QoL domains. People with mental illness in open employment (that is normal jobs rather than disability-specific activity such as sheltered workshops or day-care centres) were more satisfied with their work and economic situation than those engaged in day-care centres and those with no regular day activities (Eklund, 2009). In a review of case-control studies on QoL and well-being, people with intellectual disabilities in employment reported higher job satisfaction, self-esteem, and less depression for those in supported employment compared 
with sheltered employment (Jahoda, Kemp, Riddell, \& Bank, 2008). Additional studies have identified higher QoL for people with intellectual disabilities in open employment compared to those in sheltered employment (Eggleton et al., 1999; Kober \& Eggleton, 2005; SinnottOswald, Gliner, \& Spencer, 1991). However, no difference was found in a Spanish study by Verdugo and colleagues (2006). Benefits associated with sheltered employment in Spain included minimum wages, over-time payments, and medical benefits, and may account for high satisfaction with sheltered employment. As such, there is conflicting evidence on how different forms of employment effect QoL for people with disability. It has been suggested that sheltered and open employment foster the development of different kinds of social relationships (Hall \& Kramer, 2009) and it may be that this, combined with different QOL measures or instruments, account for the differences in QoL identified across these settings.

Employment improves financial outcomes for people with disabilities, and it is equally important to determine the broader impact on their lives (Inge, Banks, Wehman, Hill, \& Shafer, 1988). Apprenticeships and traineeships have been identified as positive vocational pathways with high graduate employment rates for people with disabilities (Cocks \& Thoresen, 2013a, 2013b; Cocks et al., 2013; Lewis et al., 2011a).

\section{Apprenticeships and Traineeships in Australia}

In Australia, apprenticeships and traineeships are courses within the broader Australian vocational education and training (VET) system. They are collectively referred to as Australian Apprenticeships (Naidu, 2011). VET provides training across a range of subject areas through a variety of training institutions. Apprenticeship and traineeship programmes are governed by a contracted arrangement, combining work and training, and can be undertaken full-time or part-time, be part of high-school education which is referred to as school-based training, and undertaken on or off the job, or through combinations (NCVER, 2011b). Typical apprenticeships or traineeships consist of $80 \%$ paid work and $20 \%$ unpaid 
study (Lewis et al., 2011a). All courses reflect workplace performance and nationally endorsed competency standards in traditional trades as well as business, retail, hospitality, and other sectors (Lewis et al., 2011b; NCVER, 2011b). Upon successful course completion, apprentices and trainees receive a nationally recognised certificate, rated I through IV. Generally, certificates I and II take one to two years to complete, whereas certificates III and IV require three to four years (Naidu). Most traineeships are shorter courses, usually between one and two years, while apprenticeships are commonly of three or four years duration (Lewis et al., 2011a, 2011b; Naidu, 2011). Group training organisations (GTOs) support more than 40,000 apprentices and trainees who are placed with host training employers during their training course on a labour hire basis. GTOs provide benefits to the host training employers including the administration of training costs and wages and will take apprentices or trainees back at any time (Lewis et al., 2011b). This form of VET provides many benefits and, for people with disabilities, is potentially an effective pathway to the labour market and further education and training. The authors are unaware of any research to date that identifies to what extent apprenticeships and traineeships enhance the quality of life of graduates with disabilities. This is despite research identifying good outcomes for apprentices and trainees with disabilities (Ball \& David, 2005; Cocks \& Thoresen, 2013a, 2013b; Cocks et al., 2013; Lewis et al., 2011a). Therefore it is the intent of this study to examine QoL using an appropriately normed instrument as part of an interview schedule that utilised a career pathway framework and developed case studies as illuminating examples.

\section{Method}

\section{Research Purpose}

This study investigated the pathways from high school to 12 months following graduation and the QoL outcomes of 30 people with disabilities who graduated with apprenticeship or traineeship qualifications between 2009 and 2011. Participants were sampled from a 
longitudinal Australian study that surveyed social and economic outcomes of a large cohort of graduates with disabilities $(n=404)$ and a comparison group of graduates without disabilities $(n=85)$. Ethics approval for the study was received from the authors' university human research ethics committee (HR 63/2012). This article describes aspects of the vocational pathways followed by the sample, and explores the relationship between QoL and some variables associated with employment.

\section{Study Design}

Face-to-face interviews were conducted by the first two authors with the sample of 30 apprenticeship and traineeship graduates in order to capture more in-depth information about training, employment, career development, and QoL of the participants. The interview focused on six components: QoL, vocational preparation in high school, employment and training before apprenticeship or traineeship, apprenticeship or traineeship experience, graduate employment and further training, and future life prospects.

Semi-structured interviews lasting 60-90 minutes were conducted in the participants' homes or a suitable public venue in early 2012. Interviews were audio-taped with the consent of interviewees. Parents were present for two younger participants. The QOL.Q was administered during the interviews.

The interview schedule was designed to capture employment, training, and opportunities for career development during high-school, post high-school but before the apprenticeship or traineeship, and 12 months following graduation. This enabled the identification of career pathways by capturing key change points and availability of support at these different stages by identifying “illustrative results and key lessons” within a case study research approach (Yin, 1993, p. 7). 


\section{Interview Participant Recruitment}

The survey was carried out in the second half of 2011 and the first few months of 2012 including stratified purposive sampling of a comparison group of graduates without disabilities to match the disability group on gender, age, and level of training. All survey participants who volunteered to participate in the interviews were living in reasonable proximity to the capital cities of three Australian states (New South Wales, South Australia, and Western Australia) were ordered by broad primary disability groups: sensory impairment, intellectual or learning disabilities, mental illness, physical disabilities, and other disabilities. Participants were selected by hand to match the full survey sample of graduates with disabilities on disability group, gender, age, apprenticeship or traineeship graduate, and employment status. Only 30 interview participants were recruited for the study due to limited resources. Four interviews were conducted to pilot the interview schedule and procedure. No changes were required and the pilot interview results have been included in the analysis. An overview of the socio-demographic characteristics and disabilities of survey and interview participants has been presented in Tables 1 and 2.

As illustrated in Table 1, there were more male survey (58\%) and interview (63\%) participants than females, which is a general characteristic of apprentices and trainees in Australia (57\% males) (NCVER, 2011a). The majority of both survey and interview participants were young adults (two-fifths 15-24 years of age and about one-third 25-34 years of age) with slightly fewer older participants in the interview group. A higher proportion of interview participants had completed an apprenticeship than among survey participants (37\% compared to $29 \%$ respectively).

Table 2 illustrates that a large proportion of research participants had intellectual or learning disabilities, nearly $40 \%$ for both the interview and survey participants. Sensory (vision and hearing) impairment constituted around 20\% of the interview and survey 
participants. Proportions of other main disabilities (head injury or acquired brain injury, medical condition, mental illness and physical disabilities) of the interview participants were similar to the survey participants.

\section{[t] Insert Table 1 near here/[t]}

\section{[t] Insert Table 2 near here/[t]}

\section{Measurement}

QoL was measured using the QOL.Q. The scale is designed and widely used to measure overall QoL of individuals with intellectual and developmental disabilities. It has 40 items with 3-point Likert-scales and is administered in an interview format. The data consists of scores from four empirically derived factors: satisfaction, competence/productivity, empowerment/independence, and social belonging/community integration. Each factor has ten items with the scores from 1 (low) to 3 (high), giving each factor a potential range of 10 30 and an overall QOL.Q score range of 40 - 120. Schalock and Keith (1993 and 2004) established unidimensionality using factor analysis, and reported a high degree of internal consistency (Coefficient Alpha $=0.90)$, test-retest reliability $(r=0.87)$, and inter-rater reliability $(r=0.83)$.

Critics of QoL ratings among people with intellectual disabilities observe that self-rated QoL among this group is often higher than intuitive and argue that this may be attributable to differences in subjective and objective QoL (Bramston, Bruggerman, \& Pretty, 2002; Cummins, McCabe, Romeo, Reid, \& Waters, 1997). Subjective QoL is derived from selfreported satisfaction whilst objective QoL is based on relatively objective quantitative categories such as the number of times in the last month the person participated in social events. A related issue is the higher level of self-reported QoL compared to that reported by proxy-respondents. The QOL.Q addresses these issues to some extent by including both 
subjective and objective questions. Furthermore, the QOL.Q norm scores decrease proportionately with more severe intellectual disabilities (decreased IQ). The findings in this study were derived through self-report by the person with disability.

\section{Results}

\section{Career Pathways}

The interviews described the experiences of the 30 interview participants using a career pathway framework. Interviews followed four stages in their vocational development: during high school, post high school (before commencing an apprenticeship or traineeship), during their apprenticeship or traineeship course, and 12 months following completing their apprenticeship or traineeship.

For each stage, interview questions focused on three issues related to vocational outcomes: employment activity, education and training, and support received to follow vocational pathways. In waves two and three of the study, interviews will explore similar issues a further two, and then three years following graduation. The pathways method enabled identification of some key vocational activities and provided a description of a small number of "typical" experiences. In the following section, analysis of the QoL data incorporated some of the vocational activities that were associated with QoL outcomes.

\section{High School}

Of the 30 interview participants, 16 (53\%) completed 12 years of high school and another four (13\%) completed Grade 11 while the remaining ten (33\%) completed Grade 9 or 10. Two older interview participants with disabilities had returned to the workforce using VET as the pathway and presented different issues to those experienced by younger participants for whom the process was embedded in the transition period from school to adult life. A total of 16 (53\%) of interview participants specified having received forms of special educational 
support at school and 26 (87\%) specified having undertaken some form of vocational development such as career counsellors; work experience organised by schools and also mediated by family members and friends; engagement in paid employment; and participation in school-based VET courses which developed into post-school enrolment in apprenticeships and traineeships. Previous research has also emphasised the importance of family support in facilitating vocational development for young people with disabilities in their transition from school (Dixon \& Reddacliff, 2001). Specialist disability services worked in partnership with schools to support some participants. Vocational experience whilst still at school provided an important stepping-off point for many participants, emphasising the key role that schoolbased vocational activity can play in the development of career pathways.

\section{Post High School}

For the 28 participants who were in transition from high school to taking up an apprenticeship or traineeship, vocational pathways included continuing school-based VET, through employment in an apprenticeship or traineeship, or taking this up very soon after leaving school (61\%); seeking work (7\%); taking up paid work (21\%)); volunteering (7\%); and further non-VET studies (4\%).

\section{Apprenticeship or Traineeship}

Accounting for the last completed apprenticeship or traineeship for all interview participants, the majority completed work-based training (77\%) compared with those undertaking schoolbased training (3\%) or a mix of school-based and work-based training (20\%). The most prominent areas of training were: finance, property, and business services (27\%); community services, health and education (13\%); and primary industry (10\%).

Twenty seven interview participants (90\%) reported receiving support to undertake and complete their apprenticeship or traineeship. On average, participants reported 1.4 sources of 
support: 12 participants (40\%) received support from specialist disability services; eight from GTOs (27\%); 17 from their training institution (57\%); 12 from their training employer (40\%); and three received support from other sources (10\%).

\section{Twelve Months Following Graduation}

A year following graduation, 26 of the interview participants were in paid work (87\%), one participant was looking for work (3\%), two participants’ main activity was further studies (7\%), and one participant was caring for a young child (3\%). Twelve participants were engaged in further VET (40\%), ten of them full-time, and some intended to move on to diploma-level courses. Sixteen participants (53\%) had remained with the employer who had hosted their training, indicating substantial vocational continuity.

\section{Case Studies}

Four brief vignettes further illustrate the vocational pathways followed by some of interview participants. Pseudonyms are used.

\section{Martin: Well-supported Career Development and Transition into Employment}

Martin, a man in his late teens with an intellectual disability, received substantial career support at school. Besides career counselling, he participated in three work-experience placements and formal VET whilst still at school. In addition to support from his teachers, external specialist support was provided from the lecturers at the college where he completed his VET, and a disability employment service facilitated and supported his traineeship with a helpful host training employer. Fellow VET students (his "mates") helped him out with his workbooks and provided advice to help him overcome difficulties. Although not employed by the host training employer following graduation, the specialist disability agency arranged for him to begin an apprenticeship with another training employer. Martin's main income source was paid employment-he earned more than AUD\$25,000 a year. His family was 
proud of his achievements. Martin’s QOL.Q score was in the 80th percentile (raw score 100 out of 120). He felt competent for his job with the training he had received. His story illustrates a well-resourced support system that worked collaboratively and effectively.

\section{Nick: The Impact of Complex Disabilities}

Nick was in his mid-twenties and had severe seizures that were not well controlled. He also had a learning disability. Although he had been with two specialist disability employment services for some years, there had been no vocational outcomes. He worked ten hours a week for a voluntary association at a low hourly pay rate to enable him to retain his disability support pension. Pension requirements limited the hours of work and income he could receive. He wanted financial security and a "proper" job in an industry with a formal wage structure. His minimal work experience at school had hampered his vocational development. The presence of seizures had influenced his work opportunities. He planned to complete a diploma course in business studies to improve his employability. Nick received financial support from his family and earned less than AUD\$5,000 a year. His QOL.Q score was below the $10^{\text {th }}$ percentile (raw score 74 out of 120). This story illustrates the impact of risks associated with both complex disabilities and a limiting income support system. This young man and his employers needed specialist advice and support which they had been unable to access.

\section{Roy: Mature Worker Issues}

Roy, a father of three, was in his late thirties and had a sensory impairment. He completed an advanced certificate after finishing high school and worked in private enterprise for some years. Later, he completed an apprenticeship and worked with a few employers as a chef. He discussed the difficulty in obtaining work as a mature age worker, including being offered and kept at the lowest wage level, and feeling exploited. Supporting a family presented 
additional challenges, however he was greatly appreciative of the support he received from his family. Roy completed an advanced, related course recently, and was still looking for work. He planned to start his own café. He received financial support from the government. Roy had been intent on up-skilling himself and planned to complete a further advanced course related to his occupation. His QOL.Q score was in the $10^{\text {th }}$ percentile (raw score 78 out of 120). His story illustrated that older persons with disabilities present different issues and transition pathways.

\section{Amy: Confidence to Succeed}

Amy was in her mid-twenties and had a sensory impairment. She undertook a two-year hairdressing apprenticeship after the completion of Grade 12. She continued with the host training employer for two years before working in other hairdressing shops. Amy experienced bullying and discrimination from co-workers and employers at some workplaces. Eventually, she started her own business and intended to take on an apprentice in the future. She was keen to complete a beauty therapy course to diversify her business. Her main source of income was through full-time paid work. She earned more than AUD\$20,000 a year. Amy believed that she was capable and skilful in her work. She was living with her parents, saving for a house and wanted eventually to start a family. Her QOL.Q score was within the 70th percentile (raw score 100 out of 120).

This story showed the determination of a young lady to follow her vocational pursuits. She rose above some negative and unpleasant experiences and was succeeding in her career with family support.

\section{Quality of Life}

All 30 interview participants completed the QOL.Q according to the administering guidelines. As illustrated in Table 3, research participants' QOL.Q raw scores are higher than 
the norm scores for the general population without developmental disabilities. There were significant differences in the QoL among the 30 interview participants. The lowest QOL.Q score of 66 reported by an interview participant is in the lowest percentile (1\% rank score) of the norm for people with developmental disabilities. However, only two participants had QOL.Q scores in the lowest decile (10\% rank score) and only six had scores in, or below the fourth decile (40\% rank score). At the other end of the spectrum, no participants were in the top percentile (99\% rank score) although three participants were in the highest fifth percentile (95\% rank score) and seven participants (23\%) were in the highest decile (90\% rank score) of the norm for people with development disabilities.

The QOL.Q scores suggested that research participants' outcomes were collectively superior to that of the general population with developmental disabilities across this measure. Although research participants included people without developmental disabilities, the type of main disabilities did not appear to have any relationship with participants' QOL.Q scores, nor did having additional disabilities (although the impact of complex disabilities appeared to be a major challenge for some participants as outlined in the pathways section). As such, including people without developmental disabilities did not impact the higher QOL.Q scores. However, recognising that all study participants had successfully completed an apprenticeship or traineeship, it is unlikely that participants are representative of all people with disabilities, generally or within specific disability classifications. Despite all participants in the lowest two quintiles being male, the differences in QOL.Q scores according to gender were not statistically significant. Similarly, the correlation between participants' age and score was not statistically significant.

\section{[t] Insert Table 3 near here/[t]}


Tables 4-6 account for the educational and employment status, self-rated work and social satisfaction, and employee benefits arranged according to QOL.Q quintiles. These outcomes were drawn from the survey instrument which interview participants had completed along with the total cohort prior to the interviews. The survey measured outcomes at the point in time participants completed the survey, up to three years following graduation. Thus, some of the outcomes reflected in Tables 4-6 vary slightly from the outcomes collated during the interviews which reflected back to 12 months following graduation.

Although the number of participants who completed the QOL.Q is small and the number in each quintile is even smaller, there are clear trends of better outcomes among participants whose QOL.Q scores are in the higher quintiles. As illustrated in Table 4, seven (64\%) of the participants who were enrolled in further education; 16 (67\%) of the participants who were employed; 10 (83\%) of the participants who were still employed by their training employer; and 11 (65\%) of the participants who were in full-time employment had QOL.Q scores in the top two quintiles. Similarly, the employee benefits outlined in Table 5 show that 11 (79\%) of the participants who had received increased work responsibilities; all three participants who had received a permanent contract; all eight participants who had received a pay rise; and the sole participant who had received a bonus of performance payment had QOL.Q scores in the top two quintiles. Participants with QOL.Q scores in the top two quintiles on average received 1.3 employee benefits, compared to 0.3 employee benefits cited among participants in the third and second quintile. No employee benefits were reported by participants in the lowest quintile.

\section{[t] Insert Table 4 near here/[t]}

[t] Insert Table 5 near here/[t]

[t] Insert Table 6 near here/[t] 
Self-rated work and social satisfaction among participants across the quintiles also reflects differentiated outcomes. All participants with QOL.Q scores in the highest quintile agreed or strongly agreed with all statements in Table 6. Of the 23 disagree or strongly disagree responses, 20 were from the quintiles 1-3. The responses by participants with QOL.Q scores in the second through fourth quintile are mixed and vary across the quintiles and statements. The majority of participants indicated good relationships with their colleagues. Participants were asked if they met people they knew through work, after work, and during weekends to enhance insight into social connections made through the workplace. Eight participants with QOL.Q scores in the highest quintile (67\%) stated that they met people from work after hours or during the weekend in the preceding month, on average once a week. In comparison, only one (8\%) participant in each of the other quintiles indicated having met people from work after hours or during the weekend (a range from two to ten times) in the preceding month. Overall, participants with QOL.Q scores in the higher quintiles had relatively better outcomes across education, employment, employee benefits, self-rated work and social satisfaction, and social connections made through the workplace than participants in the lower quintiles.

\section{CONCLUSION}

Although only a small sample of apprenticeship and traineeship graduates with disabilities were interviewed, this study reinforced the utility of apprenticeships and traineeships as effective pathways into paid employment, enhanced QoL, and social satisfaction for people with disabilities. The pathway and QoL analysis suggested that many graduates were wellsupported in their transitions from high-school into VET and employment, including support from specialist disability service providers, GTOs, their training institutions, and employer. The case studies illustrated the importance of well-supported career development for transition into employment and the challenges of complex disabilities. They also illustrated 
that mature workers may have different work issues, particularly if the onset of their disabilities occurred later in life. These are preliminary findings from a three-year longitudinal study and further data collection and analysis is required to shed light on the sustainability of outcomes, challenges, facilitators, and changes over time. Initial findings are, nevertheless, encouraging. The research participants' QOL.Q scores were higher than the general population with developmental disabilities. This suggests high QoL for apprenticeships and traineeships graduate with disabilities.

Future research should include a larger sample size which may enable disaggregated analysis across disability classifications. This study illustrates that apprenticeship and traineeship graduates with disabilities are heterogeneous with diverse circumstances, experiences, and outcomes. Further investigation into the barriers and facilitators for subgroups such as people with complex needs or disabilities, older graduates, and young people transition from high school is warranted.

\section{Acknowledgement}

NCVER provided an Australian Competitive grant to fund the three-year study into economc and social outcomes achieved by adults with disability who had completed apprenticeships and traineeships.

\section{References}

Australian Bureau of Statistics (ABS). (2012). 4102.0 Disability and work. Retrieved from http://www.abs.gov.au/AUSSTATS/abs@.nsf/Lookup/4102.0Main+Features40March +Quarter+2012.

Australian Bureau of Statistics (ABS). (2013). Disability, aging and carers, Australia: Summary of findings 2012. Retrieved from 
http://www.abs.gov.au/AUSSTATS/abs@.nsf/Lookup/4430.0Main+Features12012?O penDocument.

Australian Council of Social Service (ACOSS). (2013). Poverty in Australia. Retrieved from http://acoss.org.au/images/uploads/Poverty_Report_2013_FINAL.pdf

Australian Institute of Health and Welfare (AIHW). (2012). Australia's Health 2012. Australia's Health Series No. 12. Cat. No. AUS 156. Canberra, ACT: Author.

Ball, K., \& David, J. (2005). Apprentice and trainee completion rates. Adelaide: National Centre for Vocational Education Research.

Barišin, A., Benjak, T., \& Vuletić, G. (2011). Health-related quality of life of women with disabilities in relation to their employment status. Croatia Medical Journal, 52, 550556. doi: $10.3325 / \mathrm{cmj} .2011 .52 .550$

Bramston, P., Bruggerman, K., \& Pretty, G. (2002). Community perspectives and subjective quality of life. International Journal of Disability, Development and Education, 49, 385-397. doi: 10.1080/1034912022000028358

Campo, S. F., Sharpton, W. R., Thompson, B., \& Sexton, D. (1996). Measurement characteristics of the Quality of Life Index when used with adults who have severe mental retardation. American Journal on Mental Retardation, 100, 546-550.

Campo, S. F., Sharpton, W. R., Thompson, B., \& Sexton, D. (1997). Correlates of the quality of life of adults with severe or profound mental retardation. Mental Retardation, 35, 329-337.

Campolieti, M. (2002). Disability and the labor force participation of older men in Canada. Labour Economics, 9, 405-432. doi:10.1016/S0927-5371(02)00051-9

Chow, S. M. K., Lo, S. K., \& Cummins, R. A. (2005). Self-perceived quality of life of children and adolescents with physical disabilities in Hong Kong. Quality of Life Research, 14, 415-423. doi:http://dx.doi.org/10.1007/s11136-004-0728-8 
Cocks, E., \& Thoresen, S. H. (2013a). Barriers and facilitators affecting course completions by apprentices and trainees with disabilities. Adelaide: National Centre for Vocational Education Research.

Cocks, E., \& Thoresen, S. H. (2013b). Social and Economic Outcomes from VET in Schools for People with Disabilities: Initial Findings from an Australian National Longitudinal. In AVETRA $201316^{\text {th }}$ Annual Conference, April 3-5, Esplenade Hotel, Fremantle, WA: AVETRA Association.

Cocks, E., Thoresen, S. H., \& Lee, E. A. L. (2013). Employment and related economic outcomes for Australian apprenticeship and traineeship graduates with disabilities: Baseline findings from a national three-year longitudinal study. Journal of Vocational Rehabilitation, 39, 205-217. doi: 10.3233/JVR-130654

Cummins, R. A., McCabe, M. P., Romeo, Y., Reid, S., \& Waters, L. (1997). An initial evaluation of the Comprehensive Quality of Life Scale - Intellectual Disability. International Journal of Disability, Development and Education, 44, 7-19. doi: $10.1080 / 0156655970440102$

Deloitte Access Economics. (2011). The economic benefits of increasing employment for people with disability. Sydney, NSW: Access Economics Pty Ltd.

Dixon, R. M., \& Reddacliff, C. A. (2001). Family contribution to the vocational lives of vocationally competent young adults with intellectual disabilities. International Journal of Disability, Development and Education, 48, 193-206. doi:

$10.1080 / 10349120120053667$

Eggleton, I., Robertson, S., Ryan, J., \& Kober, R. (1999). The impact of employment on the quality of life of people with an intellectual disability. Journal of Vocational Rehabilitation, 13, 95-107. 
Eklund, M. (2009). Work status, daily activities and quality of life among people with severe mental illness. Quality of Life Research, 18, 163-170. doi: 10.1007/s11136-008-94315

Evans, J., \& Repper, J. (2000). Employment, social inclusion and mental health. Journal of Psychiatric and Mental Health Nursing, 7, 15-24. doi: http://dx.doi.org.dbgw.lis.curtin.edu.au/10.1046/j.1365-2850.2000.00260.x

Falba, T. A., Sindelar, J. L., \& Gallo, W. T. (2009). Work expectations, realizations, and depression in older workers. The Journal of Mental Health Policy and Economics, 12, 175-186.

Felce, D., \& Perry, J. (1995). Quality of life: Its definition and measurement. Research in Developmental Disabilities, 16, 51-74. doi:10.1016/0891-4222(94)00028-8

Gold, D., Shaw, A., \& Wolffe, K. (2005). The status of Canadian youth who are blind or visually impaired: A study of lifestyles, quality of life and employment. International Congress Series, 1282, 1148-1152. doi:10.1016/j.ics.2005.05.026

Hall, A. C., \& Kramer, J. (2009). Social capital through workplace connections: Opportunities for workers with intellectual disabilities. Journal of Social Work in Disability \& Rehabilitation, 8(3-4), 146-170. doi: 10.1080/15367100903200452

Inge, K. J., Banks, P. D., Wehman, P. H., Hill, J. H. \& Shafer, M. S. (1988). Quality of life for individuals who are labelled mentally retarded: Evaluating competitive employment versus sheltered workshop employment. Education and Training in Mental Retardation, 23(2), 97-104.

Jahoda, A., Kemp, J., Riddell, S., \& Bank, P. (2008). Feelings about work: A review of the socio-emotional impact of supported employment on people with intellectual disabilities. Journal of Applied Research in Intellectual Disabilities, 21, 1-18. doi: 10.1111/j.1468-3148.2007.00365.x 
Jones, M. K., Latreille, P. L., \& Sloane, P. J. (2006). Disability, gender, and the British labour market. Oxford Economic Papers, 58, 407-449. doi: 10.1093/oep/gpl004

Kidd, M. P., Sloane, P. J., \& Ferko, I. (2000). Disability and the labour market: An analysis of British males. Journal of Health Economics, 19, 961-981. doi: 10.1016/S01676296(00)00043-6

Kober, R., \& Eggleton, I. R. C. (2005). The effects of different types of employment on quality of life. Journal of Intellectual Disability Research, 49, 756-760. doi: 10.1111/j.1365-2788.2005.00746.x

Lewis, G., Thoresen, S. H., \& Cocks, E. (2011a). Post-course outcomes of apprenticeships and traineeships for people with disability in Western Australia. Journal of Vocational Rehabilitation, 35, 107-216. doi: 10.3233/JVR-2011-0558

Lewis, G., Thoresen, S. H., \& Cocks, E. (2011b). Successful approaches to placing and supporting apprentices and trainees with disability in Australia. Journal of Vocational Rehabilitation, 34, 181-189. doi: 10.3233/JVR-2011-0546

Merton, R., \& Bateman, J. (2007). Social inclusion: Its importance to mental health. Sydney, NSW: Mental Health Coordinating Council Inc.

Moore, M. E., Konrad, A. M., Yang, Y., Ng, E. S. W., \& Doherty, A. J. (2011). The vocational well-being of workers with childhood onset of disability: life satisfaction and perceived workplace discrimination. Journal of Vocational Behavior, 79, 681698. doi: 10.1016/j.jvb.2011.03.019

Naidu, R. (2011). VET glossary. Retrieved from http://www.ncver.edu.au/publications/2029.html

National Centre for Vocational Education Research (NCVER). (2011a). Australian vocational education and training statistics: Apprentices and trainees 2010 - annual. Adelaide: NCVER. 
National Centre for Vocational Education Research (NCVER). (2011b). Students with a disability. Retrieved from http://www.ncver.edu.au/publications/2394.html.

Organisation for Economic Co-operation and Development (OECD). (2010). Sickness, disability and work: Breaking the barriers. A synthesis of findings across OECD countries. Paris: OECD Publishing.

Rapley, M., \& Lobley, J. (1995). Factor analysis of the Schalock and Keith (1993) Quality of Life Questionnaire: A replication. Mental Handicap Research, 8, 194-202. doi: 10.1111/j.1468-3148.1995.tb00155.x

Schalock, R. L., \& Keith, K. D. (1993 and 2004). Quality of Life Questionnaire manual. 1993 Manual and 2004 revision. Worthington, Ohio: IDS Publishing Corporation.

Sciulli, D., Gomes de Menezes, A., \& Vieira, J. C. (2012). Unemployment duration and disability: Evidence from Portugal. Journal of Labor Research, 33, 21-48. doi: 10.1007/s12122-011-9120-y

Sinnott-Oswald, M., Gliner, J. A., \& Spencer, K. C. (1991). Supported and sheltered employment: Quality of life issues among workers with disabilities. Education and Training in Mental Retardation, 26(4), 388-397.

Turner, J. B., \& Turner, R. J. (2004). Physical disability, unemployment, and mental health. Rehabilitation Psychology, 49, 241-249. doi: 10.1037/0090-5550.49.3.241

Verdugo, M. A., Jordán de Urríes, F. B, Jenaro, C., Caballo, C. \& Crespo, M. (2006). Quality of life of workers with an intellectual disability in supported employment. Journal of Applied Research in Intellectual Disabilities, 19, 309-316. doi: 10.1111/j.14683148.2006.00277.x

Verdugo, M. A., Prieto, G., Cabello, C. \& Pelaez, A. (2005). Factor structure of the Quality of Life Questionnaire in a Spanish sample of visually disabled adults. European Journal of Psychological Assessment, 21, 44-55. doi: 10.1027//1015-5759.21.1.44 
Virtanen, P., Vahtera, J., Broms, U., Sillanmäki, L., Kivimäki, M., \& Koskenvuo, M. (2008). Employment trajectory as determinant of change in health-related lifestyle: The prospective HeSSup study. European Journal of Public Health, 18, 504-508. doi: http://dx.doi.org/10.1093/eurpub/ckn037

Waterhouse, P., Kimberly, H., Jonas, P., \& Glover, J. (2010). What would it take? Employer perspectives on employing people with a disability. Adelaide: National Centre for Vocational Education Research.

Wilkins, R. (2004). The effects of disability on labour force status in Australia. The Australian Economic Review, 37, 359-382. doi: 10.1111/j.1467-8462.2004.00338.x

Yin, R. K. (1993). Applications of case study research. Newbury Park, London, and New Delhi: Sage Publications.

Zabkiewicz, D. (2010). The mental health benefits of work: Do they apply to poor single mothers? Social Psychiatry and Psychiatric Epidemiology, 45, 77-87. doi:

10.1007/s00127-009-0044-2 
Table 1. Socio-demographic characteristics.

\begin{tabular}{ccc}
\hline & Survey participants & Interview participants \\
\hline Gender & $n(\%)$ & $n(\%)$ \\
Females & $170(42.3)$ & $11(36.7)$ \\
Males & $232(57.7)$ & $19(63.3)$ \\
Total & $402(100.0)$ & $30(100.0)$ \\
\hline Age & $n(\%)$ & $n(\%)$ \\
$15-24$ & $169(42.8)$ & $13(43.3)$ \\
$25-34$ & $109(27.6)$ & $11(36.7)$ \\
$35-44$ & $46(11.6)$ & $4(13.3)$ \\
$45-54$ & $38(9.6)$ & $1(3.3)$ \\
$55-64$ & $30(7.6)$ & $1(3.3)$ \\
$65+$ & $3(0.8)$ & - \\
Total & $395(100.0)$ & $30(100.0)$ \\
\hline Apprenticeship or traineeship & $n(\%)$ & $n(\%)$ \\
Apprentices & $115(29.2)$ & $11(36.7)$ \\
Trainees & $279(70.8)$ & $19(63.3)$ \\
Total & $394(100.0)$ & $30(100.0)$ \\
\hline
\end{tabular}

Note: A dash (-) represents a true zero. 
Table 2. Main and addition disabilities.

\begin{tabular}{lcc}
\hline & Survey participants & Interview participants \\
\hline Main disabilities & $n(\%)$ & $n(\%)$ \\
Blind or vision impairment & $26(6.4)$ & $3(10.0)$ \\
Deaf or hearing impairment & $49(12.1)$ & $3(10.0)$ \\
Epilepsy & $6(1.5)$ & - \\
Head injury or acquired brain & $14(3.5)$ & $1(3.3)$ \\
injury & & \\
Intellectual or learning & $159(39.4)$ & $13(43.3)$ \\
Medical condition & $50(12.4)$ & $3(10.0)$ \\
Mental illness & $25(6.2)$ & $2(6.7)$ \\
Physical & $69(17.1)$ & $5(16.7)$ \\
Other & $6(1.5))$ & - \\
Total & $404(100.0)$ & $30(100.0)$ \\
\hline Additional disabilities & $n(\%)$ & $n(\%)$ \\
Blind or vision impairment & $13(9.1)$ & $1(7.7)$ \\
Deaf or hearing impairment & $11(7.7)$ & - \\
Head injury or acquired brain & $7(4.9)$ & - \\
injury & & \\
Intellectual or learning & $16(11.2)$ & $1(7.7)$ \\
Medical condition & $45(31.5)$ & $5(38.5)$ \\
Mental illness & $20(14.0)$ & $3(23.1)$ \\
Physical & $24(16.8)$ & $2(15.4)$ \\
Other & $7(4.9)$ & $1(7.7)$ \\
Total & $143(100.0)^{\mathrm{a}}$ & $13(100.0)^{\mathrm{b}}$ \\
\hline
\end{tabular}

Notes: A dash (-) represents a true zero. ${ }^{\mathrm{a}} 121$ survey participants reported additional disabilities (on average 1.2 additional disabilities); ${ }^{b} 11$ interview participants reported additional disabilities (on average 1.2 additional disabilities). 
Table 3. Participants and norm QOL.Q percentage rank scores.

\begin{tabular}{cccc}
\hline \multicolumn{2}{c}{ QOL.Q Norms - with developmental } & \multicolumn{2}{c}{ Interview participants' scores } \\
disabilities & Percentage rank & Number $(\%)$ & Cumulative (\%) \\
\hline $104+$ & $90+$ & $6(20.0)$ & $6(20.0)$ \\
$100<104$ & $80<90$ & $4(13.3)$ & $10(33.3)$ \\
$96<100$ & $70<80$ & $5(16.7)$ & $15(50.0)$ \\
$94<96$ & $60<70$ & $3(10.0)$ & $18(60.0)$ \\
$91<94$ & $50<60$ & $4(13.3)$ & $22(73.3)$ \\
$88<91$ & $40<50$ & $2(6.7)$ & $24(80.0)$ \\
$86<88$ & $30<40$ & $2(6.7)$ & $26(86.7)$ \\
$82<86$ & $20<30$ & $1(3.3)$ & $27(90.0)$ \\
$77<82$ & $10<20$ & $1(3.3)$ & $28(93.3)$ \\
$<77$ & $<10$ & $2(6.7)$ & $30(100.0)$ \\
\hline
\end{tabular}


Table 4. Educational and employment status (\%).

\begin{tabular}{lccccc}
\hline Quintile & $\begin{array}{c}\text { In further } \\
\text { education }\end{array}$ & Employed & $\begin{array}{c}\text { Employed by } \\
\text { training employer }\end{array}$ & $\begin{array}{c}\text { In full-time } \\
\text { employment }\end{array}$ & $\begin{array}{c}\text { Mean hours } \\
\text { of work }\end{array}$ \\
\hline Q5 $(\mathrm{n}=10)$ & $6(54.5)$ & $10(41.7)$ & $7(58.3)$ & $8(47.1)$ & 38.6 \\
Q 4 $(\mathrm{n}=8)$ & $1(9.1)$ & $6(25.0)$ & $3(25.0)$ & $3(17.6)$ & 37.1 \\
Q3 $(\mathrm{n}=6)$ & $1(9.1)$ & $4(16.7)$ & $1(8.3)$ & $3(17.6)$ & 20.3 \\
Q2 $(\mathrm{n}=3)$ & $2(18.2)$ & $2(8.3)$ & $1(8.3)$ & $2(11.8)$ & 38.0 \\
Q1 $(\mathrm{n}=3)$ & $1(9.1)$ & $2(8.3)$ & - & $1(5.9)$ & 29.0 \\
\hline All $(\mathrm{n}=30)$ & $11(100.0)$ & $24(100.0)$ & $12(100.0)$ & $17(100.0)$ & 34.3 \\
\hline
\end{tabular}

Note: A dash (-) represents a true zero. 
Table 5. Employee benefits (\%).

\begin{tabular}{lcccc}
\hline Quintile & $\begin{array}{c}\text { Increased } \\
\text { responsibilities }\end{array}$ & Permanent contract & Pay rise & $\begin{array}{c}\text { Bonus/performance } \\
\text { payment }\end{array}$ \\
\hline Q5 $(\mathrm{n}=10)$ & $7(50.0)$ & $2(66.7)$ & $3(37.5)$ & $1(100.0)$ \\
Q 4 $(\mathrm{n}=8)$ & $4(28.6)$ & $1(33.3)$ & $5(62.5)$ & - \\
Q3 $(\mathrm{n}=6)$ & $2(14.3)$ & - & - & - \\
Q2 $(\mathrm{n}=3)$ & $1(7.1)$ & - & - & - \\
Q1 $(\mathrm{n}=3)$ & - & - & - & $1(100.0)$ \\
\hline All $(\mathrm{n}=30)$ & $14(100)$ & $3(100.0)$ & $8(100.0)$ & \\
\hline
\end{tabular}

Note: A dash (-) represents a true zero. 
Table 6. Self-rated work and social satisfaction (valid \%).

\begin{tabular}{|c|c|c|c|c|c|}
\hline & Quintile & $\begin{array}{l}\text { Strongly } \\
\text { Agree }\end{array}$ & Agree & Disagree & $\begin{array}{l}\text { Strongly } \\
\text { Disagree }\end{array}$ \\
\hline \multirow{6}{*}{$\begin{array}{l}\text { I have a good } \\
\text { relationship with my co- } \\
\text { workers }\end{array}$} & Q5 (n=10) & 7 (77.8) & $3(25.0)$ & - & - \\
\hline & $\mathrm{Q} 4(\mathrm{n}=6)$ & - & $5(41.7)$ & - & $1(100.0)$ \\
\hline & Q3 $(n=4)$ & $1(11.1)$ & $3(25.0)$ & - & - \\
\hline & Q2 (n=2) & $1(11.1)$ & $1(8.3)$ & - & - \\
\hline & $\mathrm{Q} 1(\mathrm{n}=2)$ & - & - & $2(100.0)$ & - \\
\hline & All $(n=24)$ & $9(100.0)$ & $12(100.0)$ & $2(100.0)$ & $1(100.0$ \\
\hline \multirow{6}{*}{$\begin{array}{l}\text { I feel accepted, part of } \\
\text { the team, at work }\end{array}$} & Q5 (n=10) & $6(85.7)$ & $4(28.6)$ & - & - \\
\hline & Q $4(n=6)$ & - & 5 (35.7) & 1 (33.3) & - \\
\hline & Q3 $(n=4)$ & $1(14.3)$ & $3(21.4)$ & - & - \\
\hline & $\mathrm{Q} 2(\mathrm{n}=2)$ & - & 2 (14.3) & - & - \\
\hline & $\mathrm{Q} 1(\mathrm{n}=2)$ & - & - & $2(66.7)$ & - \\
\hline & All $(n=24)$ & $7(100.0)$ & $14(100.0)$ & $3(100.0)$ & - \\
\hline \multirow{6}{*}{$\begin{array}{l}\text { Work is a very important } \\
\text { part of my life }\end{array}$} & Q5 (n=10) & 5 (38.5) & $5(50.0)$ & - & - \\
\hline & $\mathrm{Q} 4(\mathrm{n}=6)$ & 3 (23.1) & $3(30.0)$ & - & - \\
\hline & Q3 (n=4) & $2(15.4)$ & $2(20.0)$ & - & - \\
\hline & $\mathrm{Q} 2(\mathrm{n}=2)$ & $1(7.7)$ & - & $1(100.0)$ & - \\
\hline & Q1 (n=2) & $2(15.4)$ & - & - & - \\
\hline & All $(n=24)$ & $13(100.0)$ & $10(100.0)$ & $1(100.0)$ & - \\
\hline \multirow{6}{*}{$\begin{array}{l}\text { I am happy with my } \\
\text { current working situation }\end{array}$} & Q5 (n=10) & $6(75.0)$ & $4(30.8)$ & - & - \\
\hline & Q $4(\mathrm{n}=8)$ & $2(25.0)$ & $6(46.2)$ & - & - \\
\hline & Q3 $(n=5)$ & - & $1(7.7)$ & $3(60.0)$ & 1 (33.3) \\
\hline & $\mathrm{Q} 2(\mathrm{n}=3)$ & - & $2(15.4)$ & $1(20.0)$ & - \\
\hline & Q1 (n=3) & - & - & $1(20.0)$ & $2(66.7)$ \\
\hline & All $(n=29)$ & $8(100.0)$ & $13(100.0)$ & $5(100.0)$ & $3(100.0)$ \\
\hline \multirow{6}{*}{$\begin{array}{l}\text { I am happy with my } \\
\text { current social life }\end{array}$} & Q5 (n=10) & $5(55.6)$ & $5(29.4)$ & - & - \\
\hline & $\mathrm{Q} 4(\mathrm{n}=8)$ & $1(11.1)$ & $6(35.3)$ & $1(100.0)$ & - \\
\hline & Q3 $(n=6)$ & $2(22.2)$ & $3(17.6)$ & - & 1 (33.3) \\
\hline & Q2 (n=3) & - & 3 (17.6) & - & - \\
\hline & Q1 $(n=3)$ & 1 (11.1) & - & - & $2(66.7)$ \\
\hline & All $(n=30)$ & $9(100.0)$ & $17(100.0)$ & $1(100.0)$ & $3(100.0)$ \\
\hline \multirow{6}{*}{$\begin{array}{l}\text { I am happy with my life } \\
\text { overall }\end{array}$} & Q5 (n=10) & $6(66.7)$ & $4(23.5)$ & - & - \\
\hline & Q $4(\mathrm{n}=8)$ & $1(11.1)$ & 7 (41.2) & - & - \\
\hline & Q3 (n=6) & 1 (11.1) & 3 (17.6) & $2(100.0)$ & - \\
\hline & Q2 (n=3) & 1 (11.1) & $2(11.8)$ & - & - \\
\hline & Q1 (n=3) & - & $1(5.9)$ & - & $2(100.0)$ \\
\hline & All $(n=30)$ & $9(100.0)$ & $17(100.0)$ & $2(100.0)$ & $2(100.0)$ \\
\hline
\end{tabular}

Note: A dash (-) represents a true zero. 